tioning of nature are oftentimes more precious than eloquent speeches; these are the men whose experiences worked into a few clear ideas, packed into a few awkward sentences and spoken in so many minutes, will sometimes bring to a conclusive close the discussions of many days. And when you cannot induce such men to write, you may tempt them successfully to speak, and the temptation will not be made more difficult, nor the responsibility in speaking less, by the knowledge that their words will be preserved in that storehouse of facts, experiments, and reflections which this Society will give to the generations that follow after this.

And as of like, although not equal importance, I shall venture to ask the Council to permit the publication in the Transactions of the reply made by the author of a paper to the criticisms which it has elicited. After reading in one of our journals the record of some interesting and important debate in which various, and perhaps contradictory, views have been advanced, we are told that "the author having replied, the Society adjourned." But what the author exactly said, how he dealt with the facts, cases, and criticisms adverse to his views, what he admitted or what he refuted, whether the case collapsed or succeeded, we are not informed. And thus, deprived of the most important evidence of the most important witness, we decide the case not according to evidence, which is in complete, but according to prepossessions, which neither necessarily nor usually influence us aright.

And now that our work awaits us, let us turn to it with justly attempered minds. For surely the burden of it is not mere occupation or interest, not mere success or failure, not mere profit or loss, not mere distinction for ourselves, nor even honour for the profession to which we belong. The true and serious burden of our work as we smoothly say so often, and entirely realise so seldom, is the prevention of disease, the relief of suffering, and the prolongation of life. And this is the burden of it, not in a loose and general sense, but in a solemn and particular sense ; it is the burden of it as it affects not merely many persons, but one person, one with whom we have to deal as if he were the sole object of interest and importance in the world, as if all the momentous possibilities of life and death, of the preservation or the destruction of the family life, and of all the good or evil which might issue out of recovery or of death, were centred in him, and depending upon us. Important as our work thus is to the life and welfare of the individual and the family, it is not less important to the life and welfare of the State and the world. For this work, as it is sound or unsound, successful or unsuccessful, affects, for good or evil, the numbers of the population and its physical constitution, the supply of labour and the sources of wealth, the education of the young and the direction of their energies, the moral conditions of society and the objects of political organisations, the development of the race and the fulfilment of its destinies. Such reflections, common as they are, serve to remind us of what our familiarity with them makes us forget-the momentous and far-reaching influences of our work, and of the solemn responsibilities which lie upon us in undertaking and discharging it. Such reflections may further help us to cherish the spirit of self-sacrifice in active endeavours to overcome our ignorance of disease, till at last, with fulness more or less, knowing and foreseeing, preventing or controlling, stilling pain or curing disease, repulsing death and renewing the conditions of continuing life, we may justify the boast of our father, Hippocrates, and to men in their extremities of need give help like gods.

I cannot close these desultory and imperfect remarks without adverting to the honour which you have conferred upon me in electing me to the presidential chair. It is an honour whicb, although unanticipated and unsought, is not unvalued. I regard it, indeed, as the highest honour which I or any physician could receive. For titular honours may be got by Royal favour or the influence of a great Minister, or may fall upon one through accidents of position and of service. But this honour no favour, influence, or accident can purchase. It is a spontaneous gift of the profession, and the recipient of the honour must be free from srave reproach, and at least credited with some sort of merit.

I do not deceive myself with the thought that I am sufficiently worthy of this great honour, nor do I forget that there are others before me worthier of it than I. But I am not here to-night to quarrel with your judgment; humbly and gratefully accepting it, I shall strive to justify it by endeavouring in singleness of heart and fervour of purpose to co-operate with you in the divine work which you are loing for the relief of suffering, the advancement of knowledge, and the higher discipliue of ourselves for the better service of both.

\section{DIGITAL EXPLORATION OF THE BLADDER, IN SIX OF WHICH VESICAL TUMOUR WAS REMOVED.}

BY SIR HENRY THOMPSON,

SURGEON EXTRAORDINARY TO HIS MAJESTY THE KING OF THE BELGIANS, CONSULTING SURGEON AND EMERITUS PROFESSOR OF CLINICAL SURGERY TO UNIVERSITY COLLEGE HOSPITAL, ETC. ETC.

AT the meeting of the Royal Medical and Chirurgical Society of January 23rd last I stated that, for the purpose of diagnosis in exceptionally obscure cases of urinary disease, I had of late performed a limited incision of the perineum carried to the membranous urethra only, and sufficing to enable me to carry the index-finger to the neck of the bladder, after which, by supra-pubic pressure under complete anæsthesia, the whole of the interior of the bladder might be examined by the finger, and its condition be easily determined. I stated in my paper, in language the most distinct I could adopt, that the incisions in question had been frequently employed for two centuries at least for stricture, retention, \&c., but that they had not been employed for the purpose of making the diagnostic examination above described, and, moreover, that such examination became possible only since we have had the power to produce at will complete relaxation of the patient's abdominal muscles by means of ether and similar agents ; and I claimed this proceeding to be a new mode of diagnosing such obscure conditions, and also of treating them when, as has often happened, the incisions made have sufficed also to enable me to take away a tumour or other source of disease, not removable otherwise than by operation. In order to illustrate and support these statements I append very brief notes of every case in which $I$ have made this exploratory incision, so as to enable the profession to judge of the proceeding and of its results. I have during the last two years and a half met with thirteen cases in the male of obscure disease in which $I$ deemed it right to employ digital examination of the bladder. I add one case of dilatation of the urethra in the female, because tumour was present and was removed, this being a proceeding which may be regarded as analogous to that above adopted for the male ; and I think it will be regarded as a very striking fact - to none has it been more unexpected than it has been to myself-that among these fourteen cases I have found and removed vesical tumour of considerable size in no less than six of them.

CASE 1.-T. R-, aged twenty-nine. I crushed an oxalate of lime calculus on Aug. 5th, 1880. Symptoms were very slightly relieved, and he became worse in the autumn. The condition being obscure, I operated on Nov. 6th by perineal urethrotomy, Mr. Ceely, of Aylesbury, and others, present. I found a fibrous polypoid growth (Fig. 1), and removed it with the forceps. He made a rapid recovery, and is perfectly well now and actively engaged in business. He was present at the lecture on the 29 th ult.

CASE 2. - A gentleman, aged forty-eight. Had been the subject of painful frequent micturition for several years, and of slight hromaturia, without obvious cause. On June 27 th,

1881, I operated, finding no specially morbid condition. The tube was retained in the wound for a week. He was 
much relieved, and has been better ever since, although still troubled with the same symptoms, but notably less severe.

CASE 3.-A gentleman, aged fifty-two. I performed lateral lithotomy for a large uric-acid stone on June lst, 1880 . He made a good recovery, but was afterwards troubled with phosphatic deposits and bleeding. Nothing was found by careful search except a small concretion on two occasions hence I operated on June 17th, 1881, removing some phosphatic deposit closely adhering to the inner coat, retained the tube a week, and then withdrewit. The wound rapidly healed, and he has been better since, but not altogether free from alkaline phosphatic urine.

CASE 4.-A gentleman, aged sixty-eight. I crushed a uric-acid calculus on March 18th, 1881. He became unable to empty his bladder from prostatic hypertrophy, and used the catheter habitually. A year after he began to lose blood daily, not from the catheter, which he used with great ease. Careful sounding failed to detect a cause. He was now very feeble, and I had the advantage of consultation with Sir W. Jenner, who agreed that exploration would be desirable. On Feb. 10th, 1882, I did this, and found closely adhering to the coat of the bladder a scale of phosphatic deposit, which I removed with the finger-nail, tying in a tube for seven days. The bleeding soon ceased, and has never reappeared. He is now enjoying better health and more activity than for a long time past.

CASE 5.-A gentleman, aged sixty, with hypertrophied prostate, who passed all urine by catheter, at the rate of sixteen times in the twenty-four hours. I operated on March 20th, 1882, retaining a tube in the wound, by which all the urine passed for seven days. The relief was remarkable. Soon after the wound healed, and the catheter was employed only six times in the twenty-four hours, while the patient's health and strength greatly improved, and has con. tinued so. Seen with Dr. Chepmell and others.

CASE 6. - A lady, aged thirty, the subject of severe cystitis and hæmaturia at intervals for five years. I dilated
FIG. 2.

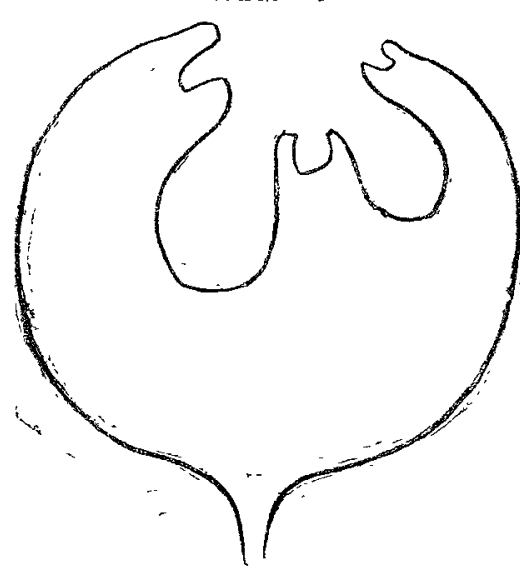

Form and situation of tumour in the bladder. (Case 6.) the urethra and explored the bladder with the finger, discovering a poly. poid tumour of considerable size (Fig. 2), and removing it with the forceps. She made an excellent recovery, the pain, frequent micturition, and bleeding, all disappearing before the end of the month. Seen with Dr. Philson of Cheltenham. She was reported in good health, free from symptoms, in October.

CASE 7. - A gentle. man, aged seventy-two. I crushed a phosphatic stone in Feb. 1878. He passed most of his urine by catheter, and had small deposits removed subsequently. In the winter of 1851-82 his symptoms became severe and distressiog, and were controlled only by morphia. Sounding detected no adequate cause. He became very feeble, and was seen by Sir W. Jenner, who assented to the operation as the best chance of relieving his sufferings. I performed the operation on June 21st, 1882, and found a sac near the neck of the bladder containing a calculus the size of a large bean, which I turned out with my finger. His sufferings were completely relieved and all necessity for catheterism was avoided, but he sank soon after from exhaustion.

C.LSE 8.-A gentleman, ared eighty-three. Has long suffered from unusually painful and frequent micturition, the interval rarely reaching forty minutes either by day or night. He almost emptied the bladder naturally, and required his catheter once a day only: but he took morphia freely. No calculus or organic change in the urinary organs could be detected. General health excellent for his age. On Jan. 30th, 1882, I operated, finding no morbid condition, except hypertrophy of the vesical coats, placed the tube in position to withdraw the urine by, and kept it there twelve days; its presence relieved him so greatly that he was unwilling to part with it, not having been so comfortable for a year, and discontinuing the morphia altogether.
The wound rapidly healed, and he held his urine from two to three hours. He continues greatly improved at the present time.

CASE 9.-A gentleman, aged forty-six. In the spring of 1881 micturition was extremely frequent. Blood appeared first in November, subsequently abundant and mixed with phosphates. In May, 1882, he came to me with Dr. Davies

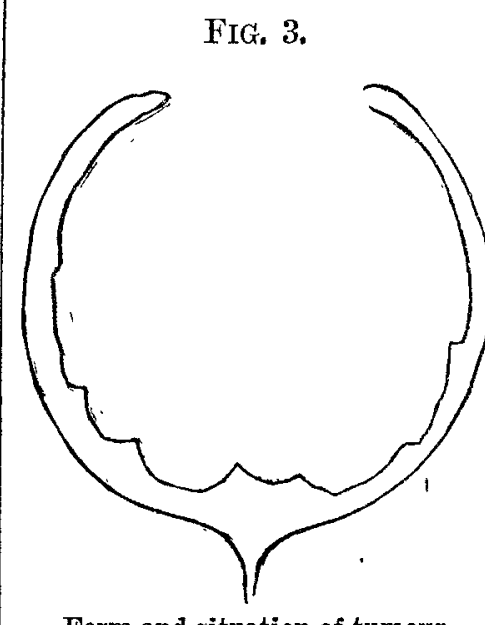

Form and situation of tumour in the bladder
(Case 9).

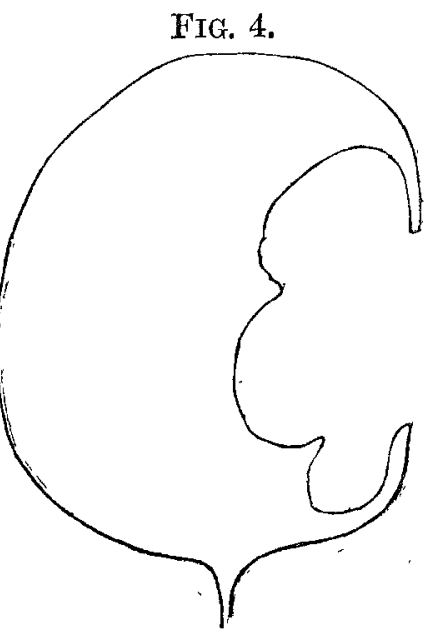

Form and situation of tumour in the bladder (Case 10) of Swansea. No calculus was found, but the interior of the bladder felt thick and soft on moving the sound. Small masses of semi-translucent material, chiefly composed of nucleated cells are passed in the urine. Returned to the country; to try styptic injections. On Nov, lst he came up with symptoms considerably increased in severity. Having no doubt that the cause was tumour, I operated on the 3rd, finding a large mass filling the bladder, springing from a widish base at the upper part. I removed the greater part by means of the forceps, half filling an ordinary tumbler with the débris (Fig. 3). A tube was tied in. The bleeding was very free, and continued to be so next day, and he sank before night.

CASE 10.-A gentleman, aged fifty-two, had suffered from hæmaturia about five years, with long intervals of freedom, particularly after the injection of perchloride of iron. On Nov. 13th, 1882, he reported the return of severe bleeding in July last, and more or less continuous since, with painful and frequent micturition, loss of strength, \&c. On Nov. 20th I operated in the presence of Dr. George Johnson and Mr. Erichsen, finding a considerable polypoid growth springing from the left side of the bladder. (Fig. 4.) This I removed with the lateral curved forceps. Bleeding was rather free for thirty-six hours; no pain. He made a steady recovery, and left town perfectly well in a month's time. Urine healthy, retained five hours. - Jan. 23rd, 1883: Has recently seen a trace of blcod after a seven-mile walk, which he felt was too much for him.

CASE 11.-A gentleman, aged twenty-four, first seen in April, 1882, who for about two years has suffered severely from pain, frequent micturition, and bleeding. The stream often commences of the natural colour and becomes bloody before ceasing. Has been sounded and treated but without benefit. After using various remedies I advised exploration. On December 15th, 1882, I performed in the usual manner. 'There was no tumour, but the whole of the mucous mem. brane of the bladder was much thickened and rugose. The tube was retained about five days. Hæmorrhage continues as before, and disappears only when a catheter is tied in and retained, the urine then continuing clear and healthy. No benefit appears at present to have resulted from the proceding.

CASE 12.-A gentleman, aged sixty-seven, saw blood in his urine six years ago, and often passed uric acid calculi. June 2nd, 1882 : Lithotrity at one sitting, removing 200 grains, Dr. Burnet present ; much bleeding afterwards. The relief was slight; frequent bleeding, during autumn, and much phosphatic deposit; notbing fuund by sounding. He is very stout and heavy.-January 17th, 1883: Perineal incision as usual; perineum very deep; found rather firm and broad tumour, left side (patient's) of bladder. Removed by forceps with some trouble; bleeding free for two days and pain severe. Resembles Fig. 4, but less pedunculated and nearer to the neck of the bladder. Tube was removed on eighth day, - Feb. 1 : No pain whatever or blood; mic- 
turition frequent. -5 th : Improving; holds water longer ; walks out for the first time to.day.

CASE 13.-A gentleman, aged fifty-two, from Cape of Good Hope. Painful micturition for a year past and great frequency; no cause discoverable by any examination I could make. Urine purulent, no blood. Health excellent. Mnch treatment before coming over without result. No relief from medicine here. - Jan. 22nd, 1883: The usual incision enabling me to explore entire surface of the bladder and finding nothing. Tied in tube, which remained eight days, during which all pain ceased, and he slept as he had not done for months; symptoms gradually improving. 31st: Took out tube ; no pain. - Feb. 5th : Some pain, not severe; urine much improved; wound healed.

CASE 14.-A gentleman, aged sixty-seven (sent by Dr. W. Anderson, of Richmond), saw blood first three years ago; last four months constant hæmaturia, increasing in amount. Stream often begins clear and leaves off deep Horid-red, seen by myself. Shreds in urine show tissue containing spindle-shaped cells and fibres.-Jan. 30th, 1883 : Operated as usual, Dr. George Johnson and Dr. B. Sewell present, removing tumour broadly pedunculated and sessile from left side (patient's) of bladder. With some trouble extracted a large mass. Pain and bleeding not considerable. Resernbles Fig. 4, but larger and broader at the base, and approaching the neck of the bladder.-Feb.2nd: Bleeding ceased ; pain slight; little feverish ; pulse $96 .-5$ th : Urine almost clear; patient doing well.

Wimpole-street.

\section{CASE OF HYSTERIA; RAPID BREATHING SIMULATING CARDIAC OR DIABETIC DYSPNEA.}

BY EDWARD MACKEY, M.D., \&C.

UYSPNEA, or rapid panting respiration, is recognised as a possibly hysterical symptom, but in certain good text-books not much stress is laid upon it. Thus Dr. Russell Reynolds says only "palpitation of heart, syncopal feelings, and dyspnoea are common enough, the latter, however, without notable change in the ratio of respiration to pulse" ${ }^{1}$ and Niemeyer: "The patients complain sometimes of very great oppression, and breathe quickly and deeply; but by excluding all disease of the respiratory passages, of the circulation of the blood, and of nutrition, which might otherwise explain the increased 'besoin de respirer' one recognises that there is only a hyperæsthesia, or at least an altered sensation." 2 The following case illustrates, however, a decided alteration "in the ratio of respiration to pulse," and at the same time a source of difficulty when cardiac or hæmic disease is present; more applicable to it is a sentence of Dr. Bristowe's : "In some cases there is actual dyspnoea, which becomes so extreme as to demand operative procedure...... without apparent cause, and with a pulse but little elevated above the normal, the respirations will suddenly rise from 40 to 50 , or even 70 to 80 in the minute, and continue thus for some minutes, or on and off for some hours, and yet without other evidence of dyspnoca or distress." 3 I had never quite appreciated this description until I met with the following case.

On Nov. 10th, 1881, at 10 P.M. I was sent for hurriedly to find a girl, aged seventeen, sitting up in bed, breathing 88 to 98 times per minute, with occasional convulsive gasps, and complaining of severe pain and oppression in the cardiac region. The face was blanched; the pulse feeble, 64; temperature $99^{\circ} \mathrm{F}$. To her family she seemed dying. Six months before this date I had attended her for aggravated chlorotic anæmia, all the symptoms of which had improved under iron, \&c., except a loud systolic basic bruit, which had persisted unchanged, and was now so loud as to obscure all other chest sounds (it was this and the cardiac pain that gave apparently a serious complexion to the case). She had seemed a sensible girl, always occupied in house-work, \&c., but recently had had disappointments, and for some days before the attack extra exertion both as to work and pleasure. The rapid breathing had commenced an hour or two before my visit. Reserving judgment as to the real nature of the attack, hypodermic morphia with atropia (in ordinary dose)

\footnotetext{
1 System of Medicine, vol. ii. 2 Handbuch, 2ter Band.
} 3 Theory and Practice of Medicine, p. 1082 . seened indicated, and certainly quieted all the symptoms; the girl slept, with relapses at intervals, and a purgative was required and given later, and then a few doses of bromide with digitalis. Next day she remained in bed, apparently improving, but on the following morning (Nov. 12th) relapsed violently; the respiration went up from 88 to 128 per minute, and in the afternoon the symptoms were so alarming that a consultation seemed desirable. Dr. Withers Moore then saw her with $\mathrm{Mr}$. Verrall (kindly taking charge in my temporary absence), and whilst recognising possible hysteria, they desired an examination of the urine with reference to diabetic dyspncea. The fact of retention for many hours was then verified, and catheterism was attempted but resisted; the secretion, however, was free from either albumen or sugar; sp. gr. 1027. At the consultation a quarter of a grain of codeia was ordered every two hours as a suitable sedative in any case. During the evening and night, respiration varied from 100 to 120 per minute; the pulse from 59 to 72 . Nourishment was taken through a glass tube, but with much difficulty, as it made the breathing more rapid and spasmodic. Two drachms of brandy every two hours. - 13 th, morning: Pulse 68 ; respiration 68 ; temperature $98^{\circ}$. Had severe headache (brandy and codeia?): better now after tea. Has pain in the left shoulder, running down the arm, and numbness in the fingers of the left hand. 3 P.M. : Crying; agitated by visitors, \&c. At 4 I received a hurried message that I "should not be in time for her last breath." Found her gasping with most urgent orthopnoea, apparently dying, the family in tears round the bed, and a clergyman giving the last ministrations of religion. Apparently she took no notice, but a slight quiver could be detected in her eyelids, and the pulse was regular, though slow and feeble. All present, except the mother, were sent away, the window was opened, morphia injected with atropia, and a blister painted over the epigastrium. In a few minutes I sent out word, in her hearing, that she was better, and this led to an explosion. She screamed, burst into violent passion, struck me, her mother, the bed, the wall, shouting, "Go away ; I don't want you." Afterwards she said she saw "an old man with a bag," and meant her blows for him. The sedatives might have developed this delusion, but the dose was an ordinary one. She was ordered valerian and bromide by mouth or rectum, and at 10 P.M. sat up for bed-making. Hulse 60 ; respiration 48. A calomel pill was given.-14th : Slept well water passed. Pulse and respiration about 60. 4 P.M. : Sent for, to find her in a wild and markedly hysterical condition, screaming, fighting, tearing clothes, curtains, \&c. ; four men were holding her. She was moderately chloroformed, became quiet and sensible in five minutes, and submitted to a turpentine enema. - 15th: Slept well from midnight. Pulse 60 ; respiration 80 , occasionally normal. Is fairly quiet, but shows temper on the slightest provocation. At 10 P.M. she had a return of delusion and anger, which chloroform quickly subdued. - 17th : Chloral with bromide was of service during the night, and valerian in the day. 25th : Has mostly lain in bed since; exhausted; but now is better, and getting up daily.-30th : A relapse.

Dec. 10th: Menses appeared, after a delay of one to two months. - 18th: Relapse as to rapid breathing and excitement. Jan. 7th, 1882 : Going on well-i.e., sits up most of the day and goes out in a Bath chair, but seems "silly at times," emotional, over-affectionate, crying easily, "You don't care for me"; says she cannot walk, no confidence in moving, staggers across the room; apparently want of control over her limbs. Her chief attention is now given to her appearance, hair-dressing, \&c., or trivial things, as dolls. This condition improved under sharp speaking, and directions in her presence that she should be left alone and not nursed too much. Zine valerianate and wine of beef and iron.

Feb. 3rd: Found that she had hidden chloral, and to-day took an overdose that produced profound sleep; this was made a lesson to her, and from this date she gradually improved and resumed house occupations.

June 6 th : Continues fairly well, but very pale and not strong; is growing; menses have intermitted once, but recurred recently; has no special pain over the heart, nor palpitation, nor dyspnoea, except on exertion, mostly when going upstairs or uphill. Pulse 80, regular, small, jerky, not visible ; no epistaxis ; no cdema. There is still a bruit, basic systolic, of maximum intensity about the third left costal cartilage, heard, though less, at the right; not propagated upwards; inaudible at apex or along the spine; it is rougher less blowing than an ordinary homic bruit, 